\title{
COUNTER-ROTATING DUAL ROTOR WIND TURBINE LAYOUT OPTIMISATION
}

\author{
Csaba Hetyei $^{a, *}$, Ferenc Szlivka ${ }^{b}$ \\ a Óbuda University, Doctoral School on Safety and Security Sciences, Népszínház street 8., 1081 Budapest, \\ Hungary \\ ${ }^{b}$ Óbuda University, Donát Bánki Faculty of Mechanical and Safety Engineering, Népszínház street 8., 1081 \\ Budapest, Hungary \\ * corresponding author: hetyei.csaba@uni-obuda.hu
}

\begin{abstract}
General energy demand is continuously increasing, thus the energy generating assets need to be optimised for higher efficiency. Wind turbines are no exception. Their maximum efficiency can be determined on a theoretical basis. The limit is approached by researches day by day, utilizing the latest developments in airfoil design, blade structure and new and improved ideas in conventional and unconventional wind turbine layouts. In this paper, we are reviewing the conventional and unconventional wind turbines and their place in smart cities. Then, an unconventional wind turbine design, the CO-DRWT (counter-rotating dual rotor wind turbine) is analysed with a CFD (computational fluid dynamics) code, varying the axial and radial distances between the two turbines. After the simulations, the power coefficients for the different turbine configurations is calculated. At the end of this paper, the simulations results are summarized and consequences are drawn for the CO-DRWT layouts.
\end{abstract}

KEYWORDS: CFD, CO-DRWT, optimisation, simulation, wind turbine.

\section{INTRODUCTION}

Nowadays, the increasing energy demand pushes engineering applications to their theoretical limit in many aspects, e.g., sustainability, more autonomous operation besides the decades-old requirements of higher performance, more economical operation and easier manufacturability. To achieve all the above mentioned requirements, the engineers need to turn to more complicated solutions: either utilizing a completely new concept or applying a new approach to an existing one. This applies to renewable energy production assets, like solar panels, wind turbines, biomass, geothermal and hydropower plants, too. In the following article, we will examine the wind turbines (WT) especially the counter-rotating dual rotor wind turbine (CO-DRWT) in this regard.

The first concept of a wind turbine was made by Heron of Alexandria in the first century. The first known wind turbine that was constructed was the Nashtifan, which was a vertical axis wind turbine (VAWT) [1. The first horizontal axis windmills appeared in the $9^{\text {th }}$ century in Great Iran, and in the $12^{\text {th }}$ century in North-Western Europe. Century by century, the structure of windmills and the blade geometry were developed. In the middle of the $19^{\text {th }}$ century, Daniel Halladay invented the American windmill, which was used for lifting water from wells [2].

The first wind turbine, which generated electricity, was invented by James Blyth in 1887, which was a vertical axis wind turbine (VAWT). Its first horizontal axis counterpart (horizontal axis wind turbine -
HAWT) was constructed by Charles Brush and builtin 1888 .

In the next decades, more and more WTs were built, the first one exceeding the $100 \mathrm{~kW}$ barrier in terms of the generated power was built in Yalta, 1931. That design is considered to be the forerunner of the currently used horizontal axis wind turbines. Thanks to the '70-' 80 s oil crisis, renewable energy sources including wind energy - came more and more into focus, and innovation in the field of WTs sped up. Nowadays, due to the fear of a nuclear accident and its environmental effects, the number of installed WTs grows progressively [3].

Nowadays, multiple WT designs exist in various sizes that make them applicable in multiple environments. Thanks to the scalability of WTs and the availability of external electrical power storage systems, they can be effectively used both as a base power plant and as a load follower power plant. In the next figure, examples of both cases are displayed: on the left-hand side (Figure 1a) North Pole's first WT, which is an example of the main power plant and on the right-hand side (Figure 1b), the WTs of Bahrain's World Trade Center, which support the building's power system.

With this level of scalability, WT's can serve as power sources for smart cities, and they can be connected to a smart grid. WT farms already use a Supervisory Control and Data Acquisition (SCADA) system, which is required for a smart city installation, too. With this, or a modified Internet of Things (IoT) 


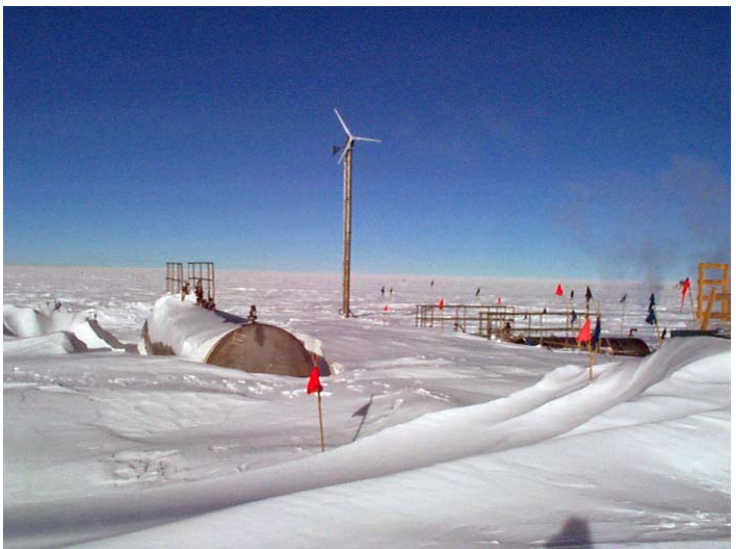

(A).

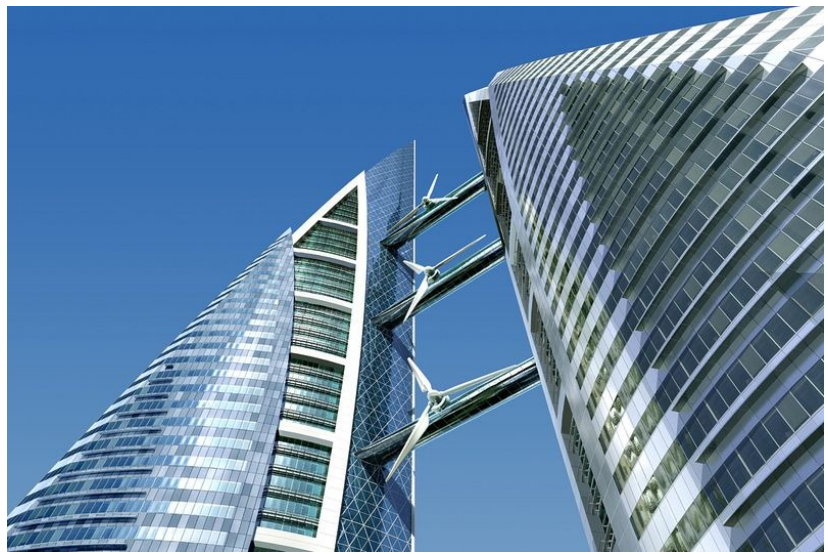

(B).

FiguRE 1. Wind turbines with different power generation roles: a) Wind Turbine at the North Pole - the main power generator 4 ; b) Wind Turbines on the World Trade Center in Bahrain - secondary power generators [5].

based system, the wind power generation data can be collected, stored and analysed centrally.

With small and large size WTs, smart and sustainable cities can be built relying on renewable energy sources. Because the demand for renewable sources is growing from the inhabitants and the governments too, see the following examples:

- Chicago City Council plans to raise the renewable portion of its municipal buildings' energy consumption to $100 \%$ by 2025 ,

- Paris City Council plans to increase the renewable portion of the city's energy consumption to $45 \%$ by 2030 and to $100 \%$ by 2050 ,

- Budapest City Council plans to increase the renewable portion of the city's energy consumption to $27 \%$ by 2030 ,

- Danish government plans to go $100 \%$ renewable by 2030 and

- Spanish government plans to achieve the same by 2050 [6, 7].

Those cities, where a large amount of energy has to be generated in a very limited space, unconventional WTs might provide a better solution. For different environments, engineers can create unique unconventional WT designs which meet the requirements specifics to the given environment. In Figure 2, there are three examples of unconventional WTs.

For unique requirements, unconventional WT designs might be necessary. These requirements might be the maximum specific energy production or additional comfort criteria (e.g. noise).

Figure 2a and 2b display examples of the former category. Figure $2 \mathrm{a}$ shows a multiple rotor wind turbine. In such designs, two or more motor rotors are placed on one tower. Alternatively, wind turbines can be equipped with additional features that help them capture more wind.
Figure 2c shows an Archimedes Screw that does not excel in terms of efficiency, but it generates power with lower noise levels due to its lower rotational speed.

The dual rotor wind turbines can be differentiated by the rotational direction of the rotors: both co- and counter-rotating dual WTs exist. Ozbay et al. [11 performed an experimental study to compare the coand counter-rotating dual rotor WTs with a single rotor wind turbine (SRWT). They found that dual rotor wind turbines produce more energy than single rotor WTs, and the counter-rotating variant is more efficient than the co-rotating dual rotor WT.

Ertuk et al. created a mathematical model for CO-DRWT to analyse the power output by changing the pitch angle and the incoming wind speed on the second rotor [12, 13, while Lee et al. carried out a measurement and CFD simulations for analysing the power output of CO-DRWT with a different yaw angle and tip speed ratio [14].

\section{Calculation of Wind turbine EFFICIENCY}

A WT's efficiency can be demonstrated with its power coefficient $\left(c_{p}\right)$, which can be calculated with the following equation:

$$
c_{p}=\frac{P_{\text {rotor }}}{P_{\text {wind }}}=\frac{M \cdot \omega}{\frac{1}{2} \cdot \rho \cdot S \cdot v_{\infty}^{3}}
$$

In the previous equation, the $c_{p}$ is the power coefficient, $P_{\text {rotor }}$ is the mechanical power generated by the rotor, $P_{\text {wind }}$ is the wind power, $M$ is the torque on the rotor, $\omega$ is the rotor's angular velocity, $\rho$ is the density of the air, $S$ is the swept area, $v_{\infty}$ is the freestream velocity.

The swept area for dual rotor wind turbines vary depending on the second turbine's position, its value can be between $S=\pi \cdot r^{2}$ and $S=2 \cdot \pi \cdot r^{2}(r$ is the swept area's radius). From 0 diameter radial shift to 1 diameter radial shift, the swept areas are shown in Figure 3 and indicated with the two rotor blades. 


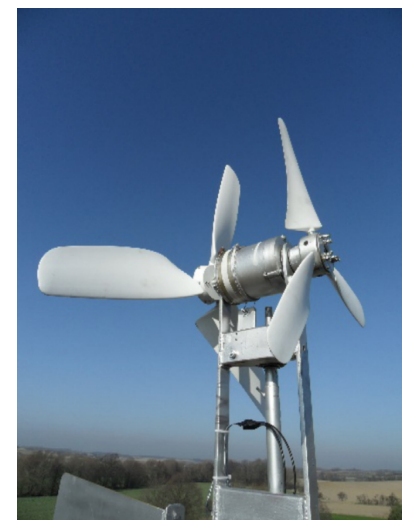

(A).

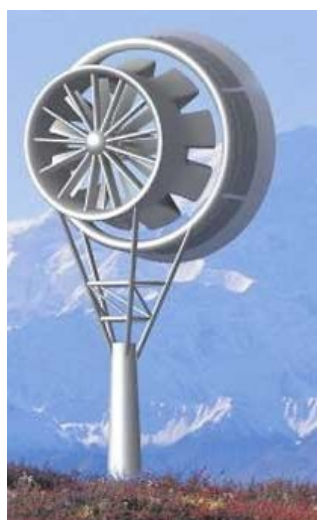

(в).

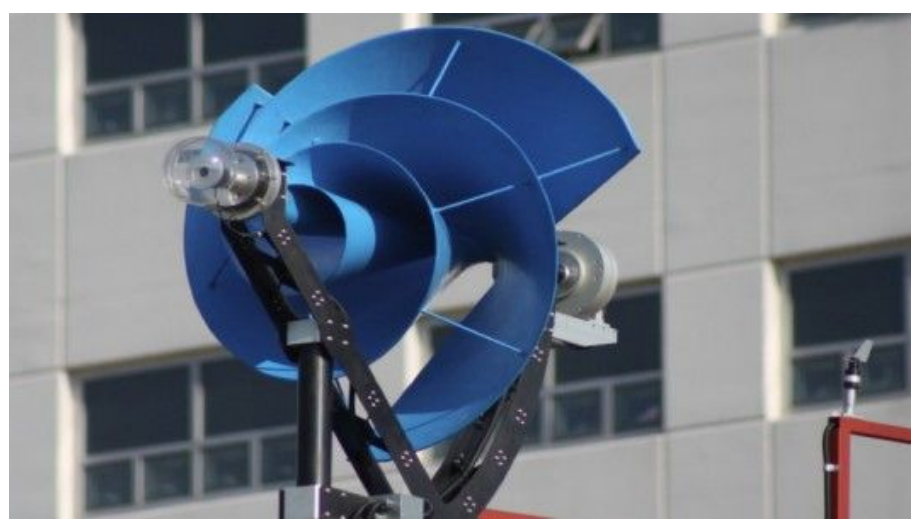

(c).

Figure 2. Unconventional WTs: a) Dual Rotor Wind Turbine [8]; b) Wind turbine with guide baffle 9]; c) Archimedes Screw Wind Turbine [10].
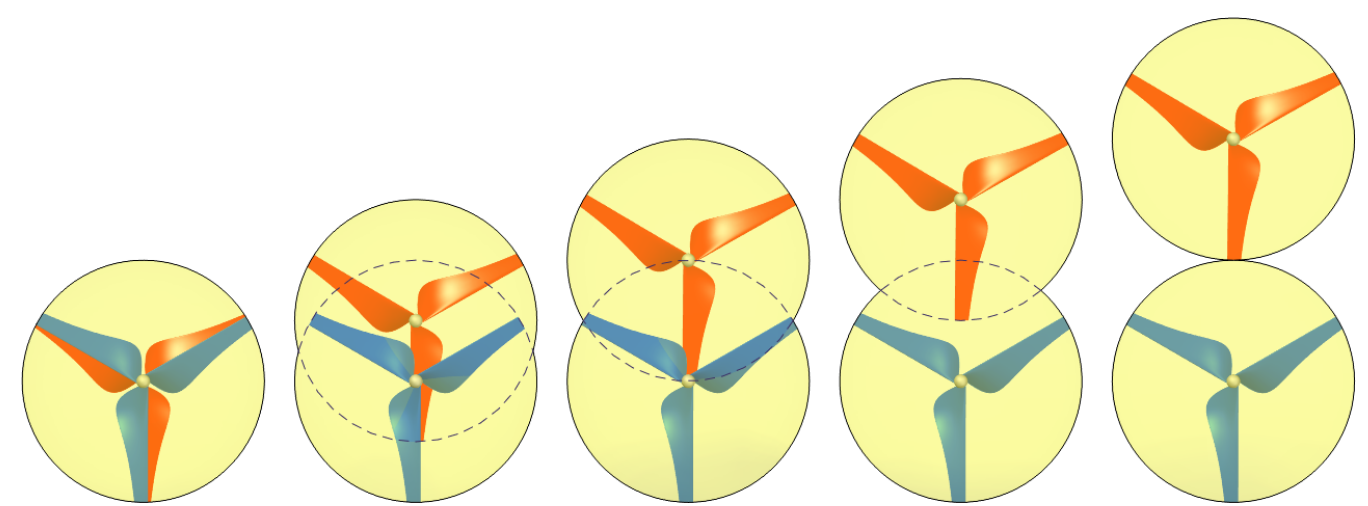

Figure 3. Swept areas for different CO-DRWT layouts (from 0 diameter to 1 diameter radial shift).

The $c_{p}$ 's maximum value is $16 / 27(59.26 \%)$ by Betz's law, and $30.113 \%$ by the GGS model [15]. The Betz limit was calculated by Betz in 1919, using a one-dimensional model, where the flow is incompressible, laminar, frictionless, the force and the pressure distribution are uniform on the turbine's blade and the rotor has an infinite number of blades. The GGS model is a curvilinear model unlike the rectilinear Betz model. Under real-life circumstances, the measured power coefficient of a wind turbine is usually between the values predicted by Betz' theorem and the GGS model.

\section{Foundations of UnSteAdy FLOWS}

The computational fluid dynamics (CFD) is a simulation tool for predicting the flow field in a given domain. For our research, we used a finite volume method (FVM) based CFD code. This method divides the computational domain into finite volumes. Continuity, momentum and energy equations are spatially discretized over the mesh generated by this subdivision. Based on the previous equations, FVM based CFD codes generally use the following transport equation [16]:

$$
\begin{aligned}
\frac{\partial}{\partial t} \int_{V} U d V+\oint_{A} \underline{F} d \underline{A}- & \\
& -\int_{V} S_{V} d V-\oint_{A} \underline{S_{A}} d \underline{A}=E
\end{aligned}
$$

In this equation, $V$ denotes an arbitrary enclosed control volume, $A$ denotes the surface of this control volume, $U$ is a conserved quantity (e.g.: mass), $F$ is the same quantity's flux over the $A$ surface, $S_{V}$ is the volumetric source of quantity $U$ over volume $V, S_{A}$ is the surface source of quantity $U$ over surface $A$ and $E$ is the error of the equation (residual).

The previous equation can be written for every cell of the mesh and solved in a system of equations. To do so, CFD codes utilise iterative methods that converge to a solution by reducing the residuals of the equations.

\section{Motivation}

In this research, a CO-DRWT was studied without the tower and the nacelle with the previously described numerical method. In our analysis, we chose two wind wheels with a $200 \mathrm{~mm}$ rotor diameter. The relative position of the two rotors varied both in the axial and radial directions. The axial distance was between 


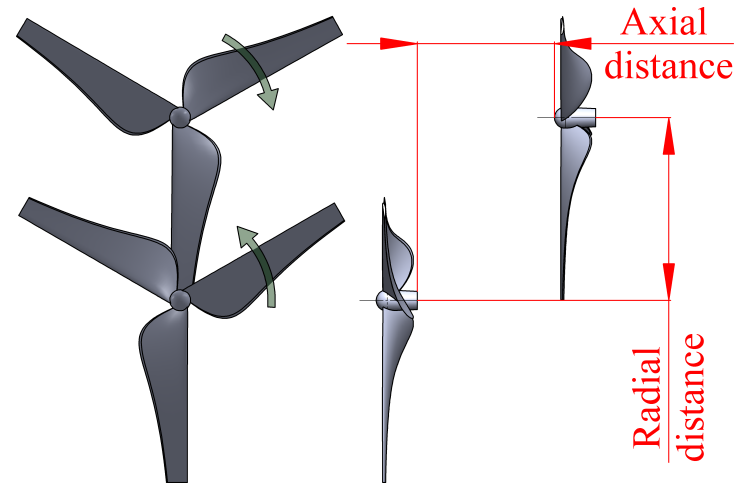

Figure 4. Studied CO-DRWT with $0.5 D$ radial and $1 D$ axial shift with rotational directions indicated.

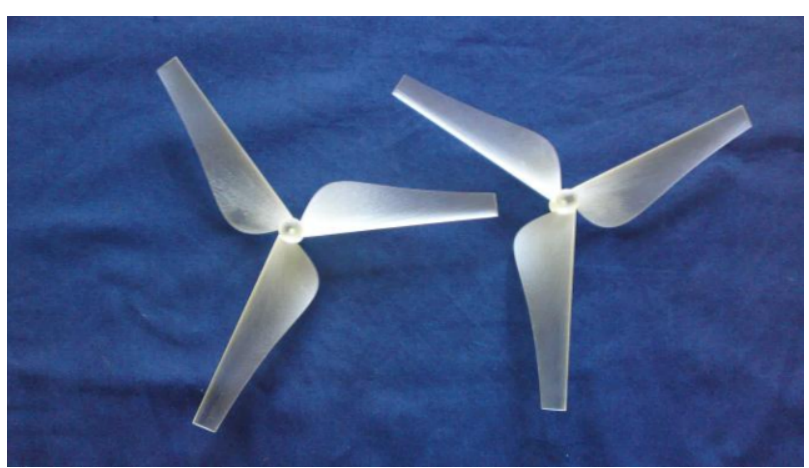

FiguRE 5. 3D printed turbines.

$0.04 D$ and $2 D$ and the radial distance was between $0 D$ and $1 D$. ( $D$ denoting the rotor diameter, e.g., $2 D$ is $400 \mathrm{~mm}$ ).

The initial positions of the rotors and their rotational directions are shown in Figure 4

For different configurations, the swept area varied. In our cases, for $0 D, 0.25 D, 0.5 D, 0.75 D$ and $1 D$ radial shifts, the areas were $31415.93 \mathrm{~mm}^{2}$, $41310.76 \mathrm{~mm}^{2}, 50548.16 \mathrm{~mm}^{2}, 58298.74 \mathrm{~mm}^{2}$ and $62831.85 \mathrm{~mm}^{2}$, respectively.

By numerical simulations, the $c_{p}$ values were calculated and evaluated for each radial and axial distance.

\section{Measurement Method}

For measurements and validation, specimens were manufactured by $3 \mathrm{D}$ printing. These are shown in Figure 5

The torque generated by the 3D printed rotors was determined by wind tunnel measurements at Szent István University. For the measurement, we used the university's wind tunnel, with a HELOIS HQ630 fan controlled with a Procon frequency converter. During the measurement, the wind speed and the tip speed ratio of the rotors were monitored and controlled, the torque was observed by a weighing motor [17. The measurement setup is shown in Figure 6

\section{Simulation parameters}

For the simulations, Mentor Graphics' FloEFD was employed with the same flow conditions as the mea-
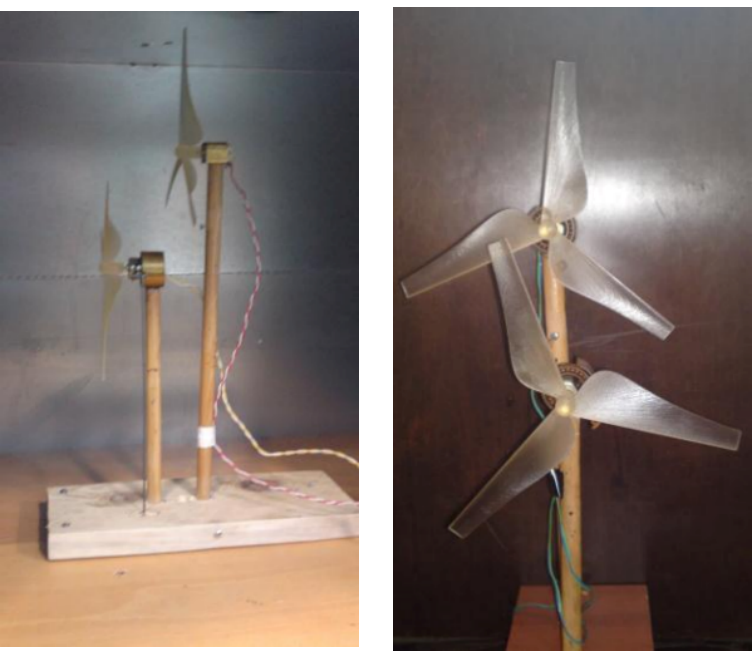

FIGURE 6 . Wind turbine models in the wind tunnel.

surement. As a fluid, "Air" was selected from the software's material database. The flow enters the computational domain through its "Front" face with a $3.79 \mathrm{~m} \cdot \mathrm{s}^{-1}$ freestream velocity. For the other boundaries of the domain, the ambient pressure was set to $1 \mathrm{~atm}$. The turbines' speed of rotation was 1447.675 RPM, which means a turbine tip speed ratio was 4 .

The tip speed ratio describes the relation between the WT's angular speed and the wind speed, and it can be calculated by equation (3), where $\lambda$ is the tip speed ratio, $\omega$ is the angular velocity, $R_{B}$ is the blade's radius and $v_{\infty}$ is the freestream velocity.

$$
\lambda=\frac{\omega \cdot R_{B}}{v_{\infty}}
$$

In the simulations, the rotation of the rotors was modelled two different ways:

- in steady-state solutions with the frozen rotor method for sweeping the whole range of dimensions in a computationally efficient way, and

- in transient solutions with the sliding mesh technique for simulating the turbulence, cross-checking the steady-state results and for validating the calculations against measurement data [17].

In a steady-state simulation, it is assumed, that the flow field will eventually converge to a stationary solution, no time-dependency is expected. As a result, it provides a single value for every quantity. In contrast, the transient solution solves the task in a fully time-dependent manner. As a result, it provides the complete time history of every quantity.

Due to the periodic geometry of the rotor, the behaviour of the turbine is quasi-static, the generated power is expected to converge to a regular, periodic, ergodic function. Hence, the results of the steadystate simulation are expected to converge to the timeaverage of the transient solution.

The steady-state simulations ran with two finishing conditions, one being a minimum iteration number of 


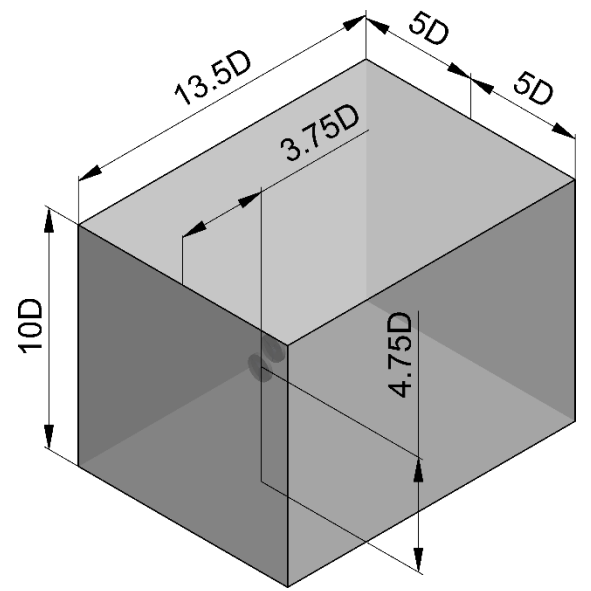

FiguRE 7. Computational domain in FloEFD.

10000 , the other being the convergence of the monitored physical values (average and maximum velocity, torque on the rotors).

The unsteady simulations were initialized with the steady-state solutions and then ran to a physical time of 0.4144582 seconds, which is equivalent to $10 \mathrm{com}-$ plete rotations.

In each simulation, the $k-\epsilon$ turbulence model was used with a two-scale wall function based on the Van Driest model.

For the studies, a rectangular computational domain was used, where the first rotor was fixed, while the position of the second rotor varied. The domain size is shown in Figure 7 .

For the spatial discretization, FloEFD's own mesher was used, which provides a cartesian mesh with cellmating and cut-cell methods. The cell count was between $2.8-3$ million, depending on the position of the turbines. The meshes are shown in the following figures (Figure 8 and Figure 9).

\section{Results}

For each configuration, the flow field was similar. Downstream the turbine, velocities are generally lower than the free flow velocity, as energy is extracted from the wind. However, near the wingtips, where vortex shedding can be observed, local velocities may be higher than the free flow velocity. The velocity distribution in the wake of the turbines is shown in the next figure (Figure 10 for a transient case with the $0.5 D$ radial shift $(100 \mathrm{~mm})$ and $0.25 D$ axial shift (50 mm) configuration.

The torque generated on the blades' surfaces was constantly monitored. This value served as the basis for the evaluation. Steady-state simulations provide a single torque value for each configuration, while transient runs generate the complete time history of the measurement. The transient torque results for one rotation are shown in Figure 11.

The $c_{p}$ values of the turbines were calculated from the torque results of the steady-state simulations using equation (1). The power coefficients of the two rotors $\left(c_{p 1}\right.$ and $\left.c_{p 2}\right)$ were added to calculate the overall $c_{p}$ of the CO-DRWT. These values are plotted in Figure 12 For a comparison, a Single Rotor Wind Turbine (SRWT) was evaluated using the same method, and its $c_{p}$ is also plotted in the same figure with a blue dashed line.

Both the steady-state and the transient results were cross-checked against the measurement data. The comparison was carried out for the $R=0.5 D$, $A=0.5 D$ case and the $R=1 D, A=0.5 D$ case with the same flow conditions, which were described in the previous section. The transient simulations predicted the overall $c_{p}$ with $10.14 \%$ and $7.93 \%$ difference, respectively, while the steady-state simulations prediction accuracy was $13.75 \%$ and $12.73 \%$, respectively.

Based on the results, the followings can be stated:

(1.) The first rotor's torque is almost constant, with a minimal fluctuation caused by turbulence (see Figure 11.

(2.) In the $A=0.5 D$ case, the torque on the second turbine shows a certain degree of fluctuation. The extent of the fluctuation is highly dependent on the radial shift: with $R=0 D$, the torque is highly disturbed by turbulence, with $R=0.5 D$, the torque shows sinusoidal fluctuations, with $R=1 D$, the fluctuations diminish (see Figure 11).

(3.) As shown in Figure 12, with our geometry, the CO-DRWT with $R=0 D$ radial shift and $A=2 D$ axial gap is the most efficient configuration.

(4.) In the examined region, the CO-DRWT with $R=1 D$ produce approximately the same $(\approx 0.5)$ power coefficient, in the case of $R=0 D$, the $c_{p}$ is increasing with the axial shift (see Figure 12.

(5.) In the $R=0.25 D$ and $R=0.5 D$ cases, the power coefficient decreases as the axial shift increases until the $A=1.25 D$ distance, after the minimum point, the $c_{p}$ increases. For the $R=0.75 D$ case, the same can be observed, but the lowest $c_{p}$ value is at $A=1 D$ distance (see Figure 12 .

(6.) Comparing the results with the measurement data, we found the transient simulations produced roughly $8 \%$ and $10 \%$ lower torque values, while the results of the steady-state simulations were about $-13 \%$ and $+14 \%$.

(7.) For each radial shift value, the maximum power coefficient of the CO-DRWT was higher than the SRWT's across the whole range of axial shifts. The maxima of the individual curves were:

(a.) 1.34 times higher for $R=1 D$,

(b.) 1.30 times higher for $R=0.75 D$,

(c.) 1.28 times higher for $R=0.5 D$,

(d.) 1.17 times higher for $R=0.25 D$,

(e.) 1.36 times higher for $R=0 D$ than the SRWT's $c_{p}$. 



Figure 8. The whole computational domain's mesh for the $R=1 D$ and $A=0.25 D$ configuration.
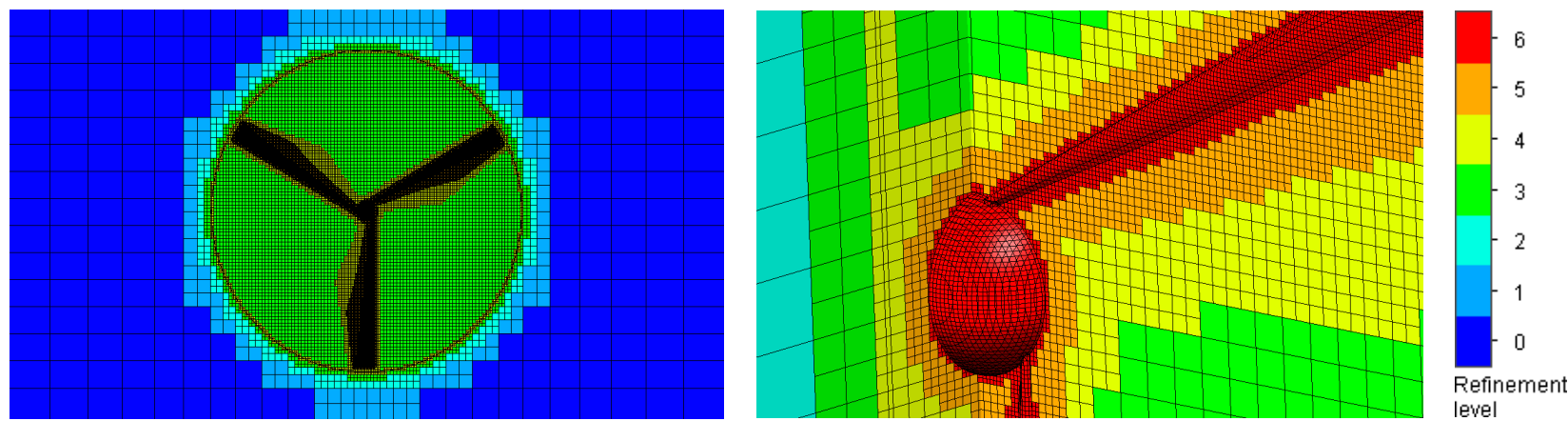

Figure 9. Mesh near the first turbine.
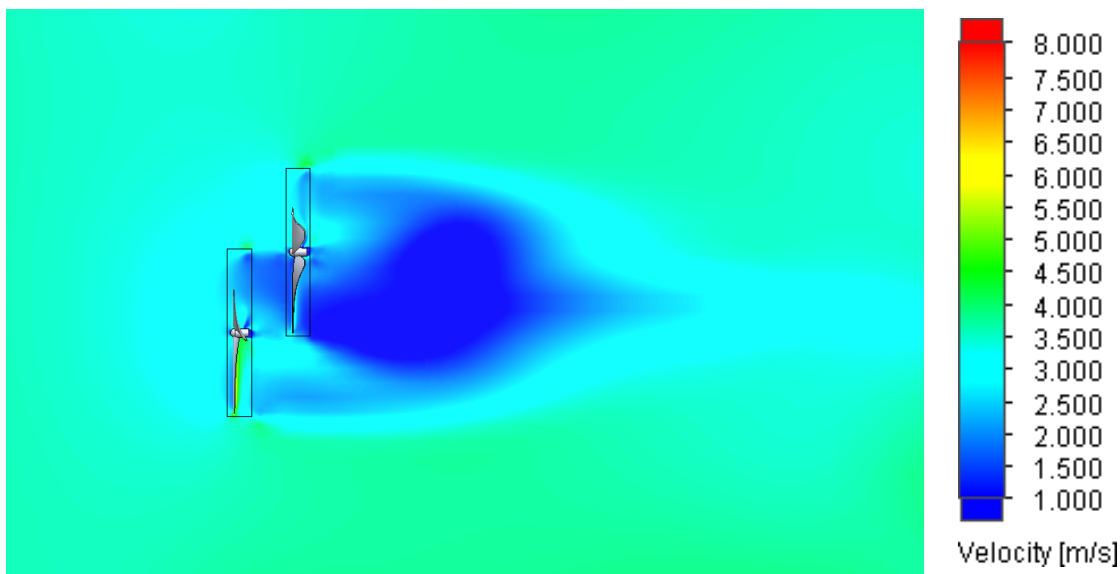

FIGURE 10. Velocity distribution in the turbines' region for the $R=0.5 D$ and $A=0.25 D$ configuration.

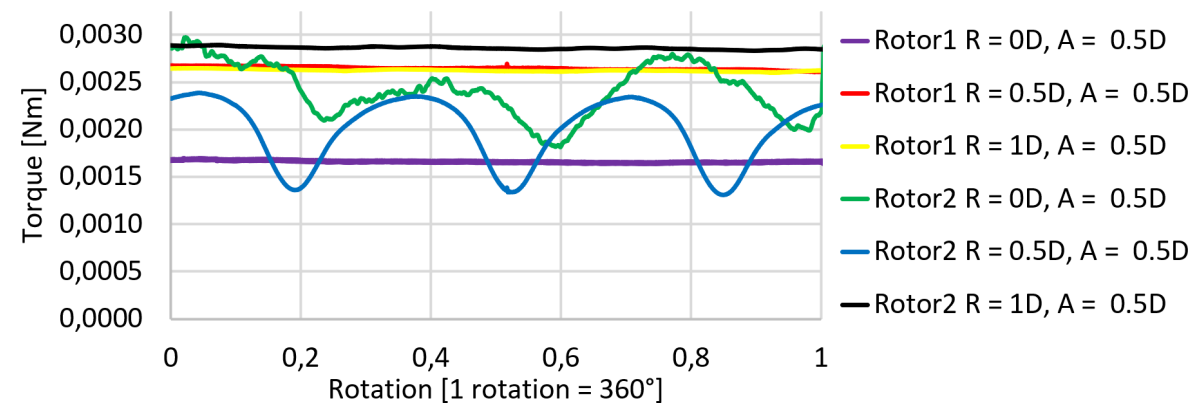

FiguRE 11. Torque values in the time domain. 


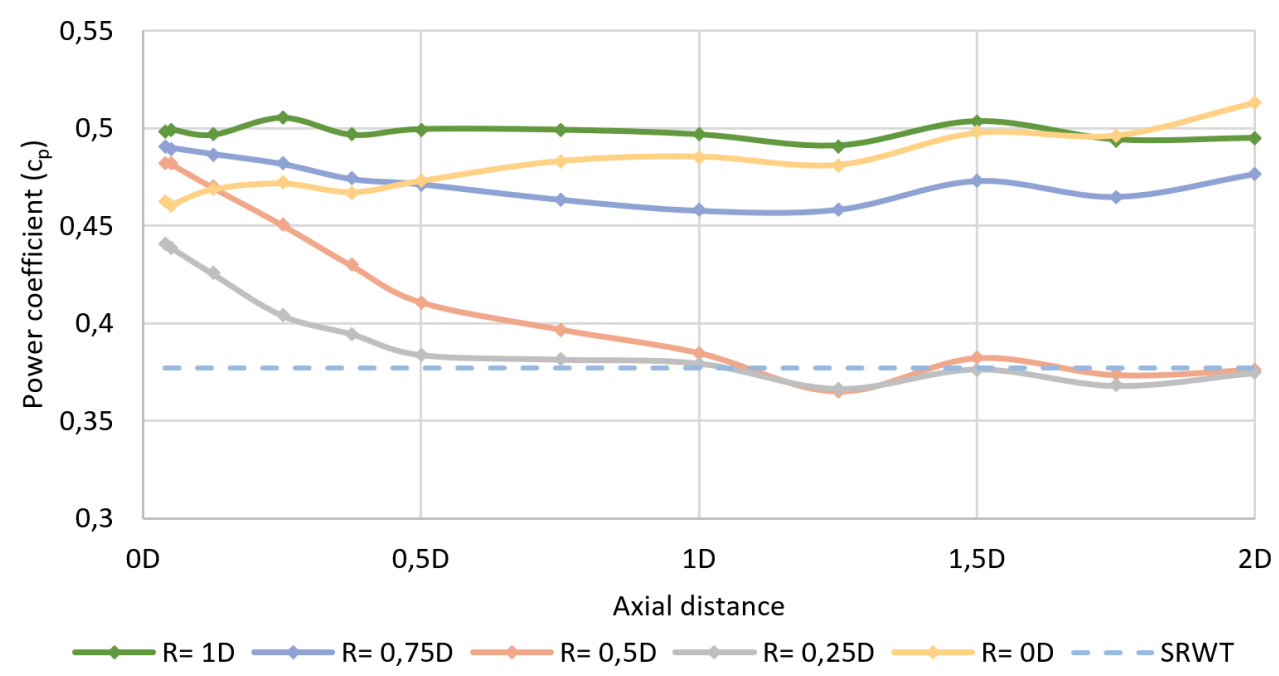

Figure 12. Power coefficient $\left(c_{p}\right)$ by the axial and radial distance.

(8.) From a comparison of the SRWT's and CODRWT's power coefficients, it can be seen that the cp curves of the CO-DRWT were:

(a.) 1.30 times higher for $R=1 D$,

(b.) 1.21 times higher for $\mathrm{R}=0.75 \mathrm{D}$,

(c.) $3 \%$ lower for $R=0.5 D$,

(d.) $3 \%$ lower for $R=0.25 D$,

(e.) 1.22 times higher for $R=0 D$ than the SRWT's $c_{p}$.

According to Statement 3 , for the $R=1 D$ case, a minimal turbine interaction is beneficial in terms of efficiency. Thus, shifting the second turbine radially has its benefits both in terms of energy generation and, probably, maintainability. However, radial shifting poses a design challenge for the turbine's nacelle and tower design and it increases the turbine's space requirement. For the $R=0 D$ case, there is a turbine interaction, but the smaller swept area has benefits for the energy generation. In this case, with the axial shift, the $c_{p}$ is growing, which is good for energy generation, maintainability and space utilization.

According to Statement 4 and 5, the CO-DRWT with $R=0 D$ and $R=1 D$ are generally efficient configurations, while the other configurations are efficient with small axial gaps.

According to Statement 5, for $R=0.25 D, R=$ $0.5 D$ and $R=0.75 D, c_{p}$ grows as the axial shift decreases. Hence, the minimal axial distance is beneficial in terms of efficiency. However, in practical cases, too small of a gap between the turbines might cause a collision of the blades due to their deformation under aerodynamic loads. For determining the minimum allowable distance, a measurement or a two-way FSI simulation is necessary.

According to Statement 7 , for the $1 D$ radial shift, the $c_{p}$ of CO-DRWT was 1.34 times higher than the SRWT's $c_{p}$. At this distance, there is an interaction between the two rotors, hence, with a greater radial shift, the interaction diminishes and $c_{p}$ can grow.

\section{Conclusions}

In this study, we analysed a counter-rotating dual rotor wind turbine, with a variable axial and radial shift. As a conclusion, we plotted the power coefficients against the axial and radial distances (Figure 12). The power coefficient was calculated based on the results of CFD simulations with the frozen rotor technique and validated against transient simulations with the sliding mesh approach and measurement data.

Based on the results of the presented study, the CODRWT has a large potential in the pursuit of more efficient ways of wind energy harvesting. Depending on the application and environment, a wisely chosen CO-DRWT configuration could generate more electrical power than the SRWT. In our opinion, in the close future, CO-DRWTs will appear in large numbers in urban areas thanks to their efficient use of space, and they will appear on wind farms, as a result of their higher energy density compared to SRWTs.

\section{REFERENCES}

[1] F. Szlivka, I. Molnár. Víz - és szélenergia hasznosítás, edutus föiskola kiadó. https :

//regi.tankonyvtar.hu/hu/tartalom/tamop412A/ 2010-0017_10_viz_es_szelenergia/index.html 2012.

[2] Windmill. https://en.wikipedia.org/wiki/Windmill.

[3] BP Statistical Review of World Energy. https://www.bp.com/content/dam/bp/ business-sites/en/global/corporate/pdfs/ energy-economics/statistical-review/ bp-stats-review-2019-full-report.pdf, 2019.

[4] Wind Turbine at North Pole. https://www . southpolestation.com/trivia/90s/drifted2.jpg. Accessed: 29 March 2020.

[5] World Trade Center in Bahrain. http://www .alternative-energy-news .info/images/ pictures/wind-powered-towers.jpg Accessed: 05 January 2020. 
[6] Renewables (em)power smart cities. Deloitte Insights. https://www2.deloitte.com/content/dam/insights/ us/articles/4971_Smart-renewable-cities/DI Smart-renewable-cities.pdf 2019. Accessed: 30 March 2020.

[7] Budapest 2024 Nonprofit Ltd. Smart Budapest - The Smart City Vision of Budapest.

https://budapest.hu/Documents/Városépítési\% 20Főosztály/Smart_Budapest_summary_ENG.pdf, 2017. Accessed: 29 March 2020.

[8] L. Romański, J. Bieniek, P. Komarnicki, et al. Estimation of operational parameters of the counterrotating wind turbine with artificial neural networks. Archives of Civil and Mechanical Engineering 17(4):1019 - 1028, 2017. https://doi.org/10.1016/j.acme.2017.04.010

[9] Unconventional wind turbines. http://www. whirlopedia.com/images/wind-turbines-elk.jpg Accessed: 08 October 2019.

[10] Bizarre wind turbines. https://cdn.trendhunterstatic.com/thumbs/ urban-wind-turbine.jpeg Accessed: 08 October 2019.

[11] A. Ozbay, W. Tian, H. Hu. Experimental Investigation on the Wake Characteristics and Aeromechanics of Dual-Rotor Wind Turbines. Journal of Engineering for Gas Turbines and Power 138(4), 2015. https://doi.org/10.1115/1.4031476
[12] E. Erturk, S. Sivrioglu, F. C. Bolat. Analysis model of a small scale counter-rotating dual rotor wind turbine with double rotational generator armature.

International Journal of Renewable Energy Research 8(4):1849 - 1858, 2018.

[13] E. Erturk, O. Gökçöl, S. Sivrioglu, F. Bolat. Modeling and analysis of a single shaft co-rotating dual rotor small wind turbine. International Journal of Mechanical Engineering and Technology 9(9):897 - 906, 2018.

[14] N.-J. Lee, M. Inagaki, T. Kanemoto. Performance of counter-rotating tandem propellers at oblique flow conditions. In IOP Conference Series: Earth and Environmental Science, vol. 240, p. 052004. 2019. https://doi.org/10.1088/1755-1315/240/5/052004.

[15] A. N. Gorban, A. M. Gorlov, V. M. Silantyev. Limits of the turbine efficiency for free fluid flow. Journal of Energy Resources Technology 123(4):311 - 317, 2001. https://doi.org/10.1115/1.1414137

[16] G. Kristóf. Áramlások numerikus modellezése, Akadémia Kiadó. https://mersz.hu/ kristof-aramlasok-numerikus-modellezese Accessed: 16 April 2020.

[17] F. Szlivka, P. Kajtar, I. Molnár, G. Telekes. CFX simulations by twin wind turbine. In International Conference on Electrical and Control Engineering 2011, pp. 5780 - 5783. Yichang, China, 2011. https://doi.org/10.1109/ICECENG.2011.6057550. 